\title{
KASUS SCABIES (SARCOPTES SCABIEI) PADA KUCING DI KLINIK INTIMEDIPET SURABAYA
}

\author{
Heri Susanto*1, Mayangsari Kartikaningrum ${ }^{2}$, Retno Sri Wahjuni3, Sunaryo Hadi \\ Warsito $^{3}$, M. Gandul Atik Yuliani ${ }^{3}$ \\ ${ }^{1}$ Pemilik Klinik Intimedipet Barata Jaya Gubeng Surabaya \\ ${ }^{2}$ Mahasiswa Fakultas Vokasi Universitas Airlangga Surabaya \\ ${ }^{3}$ Staf Pengajar Fakultas Kedokteran Hewan Universitas Airlangga Surabaya \\ e-mail: gandulatik@yahoo.com
}

\begin{abstract}
Abstrak
Sarcoptes scabiei merupakan salah satu ektoparasit yang biasa menyerang kucing. Tungau ini hidup pada kulit dengan membuat terowongan pada stratum corneum dan melangsungkan hidupnya pada tempat tersebut (Henggae et al, 2006). Penyakit skabies dapat ditularkan melalui kontak langsung dengan hewan lain yang terkena skabies atau dengan adanya sumber tungau skabies di wilayah tempat tinggal kucing (Wardhana et al, 2006). Hewan terserang mengalami penurunan kondisi tubuh, menimbulkan dampak negatif bagi pemelihara dan lingkungan.

Studi kasus ini dilakukan dengan cara mengambil data pasien kucing melalui pengamatan langsung dengan melakukan pemeriksaan fisik hewan, dilanjutkan diagnosa oleh Dokter Hewan di Klinik Intimedipet, kemudian dilakukan pengobatan skabies. Parameter yang diamati dalam kegiatan ini berupa kondisi menyeluruh kucing yang diperiksa dan penanganan yang diberikan untuk kasus yang menderita skabies.

Berdasarkan data yang diperoleh pada tabel 1 umur kucing yang terkena skabies di Klinik Intimedipet rata-rata berumur kurang dari satu tahun, kemungkinan tertular dari induk yang sudah terinfeksi scabies sebelumnya. Sedangkan dari jenisnya $80 \%$ menyerang anak2 kucing Persian yang berbulu panjang. Saran yang perlu disampaikan bahwa penyakit skabies merupakan penyakit zoonosis, sehingga apabila hewan peliharaan yang terserang penyakit skabies sebaiknya segera dilakukan pengobatan secara intensif.
\end{abstract}

Kata kunci-Scabies, kucing, klinik Intimedipet

\begin{abstract}
Sarcoptes scabiei is one of the ectoparasites that usually attacks cats. These mites live on the skin by making tunnels in the stratum corneum and carry out their lives in that place (Henggae et al, 2006). Scabies can be transmitted through direct contact with other animals affected by scabies or by the presence of a source of scabies mites in the area where cats live (Wardhana et al, 2006). Affected animals experience a decrease in body condition, causing negative impacts for the keeper and the environment. Sarcoptes scabiei is one of the ectoparasites that usually attacks cats. These mites live on the skin by making tunnels in the stratum corneum and carry out
\end{abstract}


Jurnal Biosains Pascasarjana Vol. 22 (2020) pp

(C) (2020) Sekolah Pascasarjana Universitas Airlangga, Indonesia

their lives in that place (Henggae et al, 2006). Scabies can be transmitted through direct contact with other animals affected by scabies or by the presence of a source of scabies mites in the area where cats live (Wardhana et al, 2006). Affected animals experience a decrease in body condition, causing negative impacts for the keeper and the environment.

This case study was carried out by taking cat patient data through direct observation by conducting a physical examination of the animal, followed by a diagnosis by the Veterinarian at the Intimedipet Clinic, then scabies treatment. The parameters observed in this activity are the overall condition of the cat being examined and the treatment given for cases suffering from scabies.

Based on the data obtained in table 1, the age of cats affected by scabies at the Intimedipet Clinic, on average, is less than one year old. While $80 \%$ of the types attack the long-haired Persian kittens. Suggestions that need to be conveyed that scabies is a zoonotic disease, so if pets with scabies should be treated intensively immediately.

Keywords-Scabies, cats, Intimedipet clinic 


\section{PENDAHULUAN}

Skabies adalah penyakit kulit yang sering dijumpai pada ternak dan hewan kesayangan di Indonesia yang cenderung sulit disembuhkan. Scabies merupakan salah satu penyakit yang menyerang kulit dan disebabkan oleh tungau Sarcoptes scabiei (Arlian dan Morgan, 2017). Infestasi dengan tungau Sarcoptes scabiei adalah di antara 10 penyakit kulit paling umum pada anjing yang dirujuk ke rumah sakit pendidikan dokter hewan di Amerika Serikat (Sischo et al, 1989). Meskipun infestasi Sarcoptes scabiei dilaporkan jarang terjadi pada kucing (Urquhart et al, 1996). Gejala yang ditimbulkan ketika kucing terkena skabies adalah kucing sering menggaruk bagian tubuhnya.

Manifestasi tungau Sarcoptes scabiei pada kulit akan menyebabkan terjadinya lesi kulit berupa eritema, makula, dan papula. Keadaan lesi yang parah akan membentuk keropeng pada beberapa bagian di tubuh seperti pada daerah telinga, wajah, siku, jari, dan sekitar kelamin (Taylor et al, 2007). Akibat yang ditimbulkan yaitu berupa kebotakan (alopesia) dan lesio pada kulit yang mengering dan mengeras dan menjadi keropeng, lesio ini akan cepat menyebar ke seluruh tubuh seiring dengan derajat infestasi tungau (Kelly, 1984).

Sarcoptes scabiei merupakan salah satu ektoparasit yang biasa menyerang kucing. Tungau ini hidup pada kulit dengan membuat terowongan pada stratum corneum dan melangsungkan hidupnya pada tempat tersebut (Henggae et al, 2006). Penyakit skabies dapat ditularkan melalui kontak langsung dengan hewan lain yang terkena skabies atau dengan adanya sumber tungau skabies di wilayah tempat tinggal kucing (Wardhana et al, 2006). Hewan terserang mengalami penurunan kondisi tubuh, menimbulkan dampak negatif bagi pemelihara dan lingkungan karena sifatnya yang zoonotik (Budiantono, 2004).

Skabies kemungkinan dapat memicu terjadinya reaksi alergi dan dapat meningkatkan jumlah leukosit atau sel darah putih pada tubuh. Hal ini terjadi karena leukosit merupakan sel darah yang berfungsi sebagai sistem pertahanan tubuh terhadap adanya infeksi (Yuniwarti, 2015).

\section{TINJAUAN PUSTAKA}

\subsection{Scabies (Sarcoptes Scabiei)}

Skabies atau kudis adalah penyakit kulit menular yang disebabkan oleh infestasi tungau Sarcoptes scabiei. Penyakit ini telah dikenal sejak lama, yaitu ketika Bonomo dan Cestoni mampu mengilustrasikan sebuah tungau sebagai penyebab skabies pada tahun 1689 (Montesu dan Cottoni, 1991) . Literatur lain menyebutkan bahwa skabies diteliti pertama kali oleh Aristotle dan Cicero sekitar tiga ribu tahun yang lalu dan menyebutnya sebagai "lice in the flesh" (Alexander, 1984) .

Skabies ada dalam semua populasi hewan. Varietas tungau penyebab skabies pada beberapa jenis hewan morfolginya sama, hanya berbeda dalam kesanggupannya memanfaatkan induk semang yang berlainan sehingga dari populasi tersebut timbul nama yang khas untuk masing-masing jenis (Flynn, 2002).

Sarcoptes Scabiei betina dewasa berukuran panjang sekitar $0.3-0.5 \mathrm{~mm}$ dan lebar sekitar $0.3 \mathrm{~mm}$, sedangkan yang jantan berukuran panjang sekitar $0.25 \mathrm{~mm}$ dan lebar $0.2 \mathrm{~mm}$ (Arlian, 1989). Badannya berbentuk oval dan gepeng. Stadium dewasa mempunyai 4 pasang kaki, 2 pasang merupakan pasangan kaki depan dan 2 pasang lainnya kaki belakang. Sarcoptes scabiei 
betina yang gravid mencari tempat untuk meletakkan telur dilapisan kulit (Stratum corneum) dengan membuat terowongan sambil bertelur (Saleha Sungkar, 2004).

\subsection{Patogenesis Scabies pada Kucing}

Umumnya orang tertular lewat kontak langsung, misalnya karena memegang kucing yang tertular penyakit ini atau dapat pula melalui kontak tidak langsung melalui alat - alat seperti kandang, sikat atau alat lain yang dipakai oleh kucing yang tertular skabies. Kepekaan terhadap penularan skabies tidak sama. Ada yang mudah merasa gatal - gatal, namun ada pula yang tidak merasakan apa - apa. Akibat reaksi menggaruk, sebagian kulit kucing akan terkelupas. Kulit yang terkelupas tersebut dapat membawa penyakit skabies sewaktu - waktu (Soeharsono, 2007).

Sarcoptes scabiei tinggal di dalam stratum korneum (lapisan tanduk) kulit dan memakan cairan sel. Tungau menggali hanya diplapisan bagian atas kulit dan tidak pernah sampai di bawah stratum korneum. Terowongan yang dihasilkan tampak sebagai garis tipis yang berkelok - kelok yang berwarna abu - abu atau seperti kulit dengan panjang dengan mencapai lebih dari 1 cm (CDC, 2010).

Siklus hidup Sarcoptes scabiei dari telur hingga menjadi tungau dewasa memerlukan waktu $10-14$ hari hari sedangkan tungau betina mampu bertahan hidup pada inangnya hingga 30 hari (Wardhanan, et al, 2006; CDC, 2010). Tungau betina menggali terowongan di bawah permukaan kulit dan meletakkan $2-3$ telur setiap harinya selama 6 hari berturut - turut, sehingga menyebabkan timbulnya papule pada kulit. Telur akan menetas setelah $2-3$ hari (Arlian, 1989; CDC, 2010). Telur akan hidup sebagai larva di lorong lorong lapisan tanduk kulit. Larva akan meninggalkan lorong, bergerak ke lapisan permukaan kulit, membuat saluran - saluran lateral dan bersembunyi di dalam folikel rambut. Larva berganti kulit dalam waktu dua sampai tiga hari menjadi protonimpa dan tritonimpa yang selanjutnya menjadi dewasa dalam waktu tiga sampai enam hari (Urquhart et al, 1989; Levine, 1990).

\subsection{Gejala klinis}

Umumnya gejala klinis yang ditimbulkan akibat infestasi Sarcoptes scabiei hampir sama, yaitu gatal - gatal, hewan menjadi tidak tenang, menggosok - gosokkan tubuhnya ke dinding kandang dan akhirnya timbul peradangan kulit. Bentuk eritrema dan papula akan terlihat jelas pada daerah kulit yang tidak ditumbuhi bulu. Apabila kondisi tersebut tidak segera diobati, maka akan terjadi penebalan dan pelipatan kulit disertai dengan timbulnya kerak/keropeng. Gejala tersebut timbul kira - kira dalam waktu tiga minggu pasca infestasi tungau atau sejak larva membuat terowongan di dalam kulit (Setiawan, 2016).

Gejala klinis yang ditimbulkan penyakit skabies adalah gatal - gatal, terbentuknya bintik - bintik merah, papula, dan vesikula. Antara papula satu dengan papula yang berdekatan letaknya, terlihat gambaran alur yang merupakan garis penghubung kedua papula tersebut. Keadaan tersebut dapat terjadi pada penderita skabies yang belum lama dan belum pernah diobati dengan obat anti skabies. Cara diagnosa skabies didasarkan pada gambaran gejala klinik dalam prakteknya sulit ditetapkan karena berbagai penyakit kulit lainnya memberikan gambaran klinis yang mirip dengan skabies. Oleh karena itu diagnosis harus dipadukan dengan pemeriksaan laboratorik (Setiawan, 2016).

Tungau Sarcoptes scabiei tidak mengisap darah, tetapi mengisap 
cairan diantara sel kulit. Selama aktivitas tersebut tungau betina akan mengeluarkan sekreta dan ekskreta yang menyebabkan terjadinya iritasi dan peradangan pada kulit (Wall \& shearer, 2001). Rasa gatal yang ditimbulkan oleh aktivitas tungau akan membuat kucing menggaruk dan akan menyebabkan iritasi yang lebih hebat. Kulit akan mengeluarkan cairan eksudat bening yang bilamana kering akan membuat kulit menebal dan menjadi keropeng atau pecah - pecah. Selain itu, akan terlihat kerontokan (Nahm \& Corwin, 1997).

\subsection{Diagnosis}

Dalam penegakan diagnosis penyakit kulit yang disebabkan oleh beberapa jenis tungau seperti demodekosis, skabies, dan penyakit kulit lain seperti ringworm, biasanya dilakukan pengerokan kulit (scrapping). Metode ini bertujuan untuk menemukan dan mengidentifikasi jenis parasit dengan memeriksa di bawah mikroskop. Tungau sangat sulit untuk ditemukan pada hewan, terutama pada hewan yang sudah cukup lama terinfeksi atau hewan yang baru saja dimadikan (Hammet, 1999).

\subsection{Pengobatan dan Pencegahan}

Penanganan penyakit skabies cukup sederhana, ada beberapa faktor yang harus diperhatikan. Selain berfokus pada tungau parasit, nutrisi dan manajemen pemeliharaan harus diperhatikan. Nutrisi dan manajemen pemeliharaan yang buruk akan menyebabkan hewan menjadi stress dan menurunkan imunitas hewan, sehingga menyebabkan hewan rentan terhadap penyakit lainnya (Huang et al, 1998).

Permethrin 5\% merupakan insektisida sintetik pyrethoid turunan dari chrysanthemuns yang mudah toleransi dan toksisitasnya rendah, sedikit diabsorbsi oleh kulit dan yang terabsorbsi langsung dimetabolisme oleh tubuh. Aplikasi topikal lebih baik efeknya dibanding aplikasi oral (Walton et al, 2000). Permethrin sebaiknya dibiarkan selama delapan sampai sepuluh jam berada di kulit, kemudian dapat dibilas. Pengobatan dapat diulang dalam waktu satu minggu kemudian (Buffet dan Dupin, 2003).

Ivermectin adalah antibiotik lakton makrosiklik dari kelompok avermectin, yang berasal dari Actinomicetes yang hidup ditanah yaitu Streptomices avermectalis. Obat ini digunakan secara luas untuk tungau sarcoptes pada hewan dan manusia (McCarthy et al, 2004). Selain khasiatnya sebagai anti skabies, ivermectin juga efektif mengurangi kejadian infeksi sekunder karena bakteri Streptococcus pyoderma yang menyertai skabies (Lawrence et al, 2004).

\section{METODE PENELITIAN}

Studi kasus ini dilakukan dengan cara mengambil data pasien kucing melalui pengamatan langsung dengan melakukan pemeriksaan fisik hewan, dilanjutkan diagnosa oleh Dokter Hewan di Klinik Intimedipet, kemudian dilakukan pengobatan skabies. Parameter yang diamati dalam kegiatan ini berupa kondisi menyeluruh kucing yang diperiksa dan penanganan yang diberikan untuk kasus yang menderita skabies.

Praktek kerja lapangan pilihan dilaksanakan selama satu bulan, dimulai pada tanggal 6 Januari sampai 2020 dengan 6 Februari 2020 di Klinik Intimedipet Jl. Barata Jaya II No. 52, Baratajaya, Kecamatan Gubeng, Kota Surabaya. Waktu pengambilan data mengikuti jam beroprasinya Klinik Intimedipet yaitu dari jam 08.00 sampai 17.00 dengan waktu istirahat pada jam 13.00 sampai 14.00 pada hari senin sampai sabtu. Hari minggu dan tanggal merah Klinik Intimedipet libur. 
Data pasien skabies yang diambil bulan Januari 2020 dengan pengamatan langsung, mengambil informasi dari owner dan mengambil data yang sudah ada di Klinik Intimedipet

\section{HASIL DAN PEMBAHASAN}

\subsection{Jumlah Kasus Skabies (Sarcoptes scabiei)}

Jumlah kasus skabies di Klinik Intimedipet pada interval tanggal 6 Januari sampai 6 Februari 2020 setelah dilakukan pengamatan sejumlah 6 pasien, data kasus skabies dapat dilihat pada tabel 1 .

Tabel.1 Data kasus skabies (Sarcoptes

\begin{tabular}{|c|c|c|l|}
\hline No. & Tanggal & Nama Pasien & $\begin{array}{c}\text { Jenis } \\
\text { Hewan }\end{array}$ \\
\hline 1. & 6 Jan 2020 & Kucing Miky & Domestik \\
\hline 2. & 8 Jan 2020 & Kucing Tyas & Persian \\
\hline 3. & 18 Jan 2020 & Kucing Leoni & Persian \\
\hline 4. & 18 Jan 2020 & Kucing Sincan & Persian \\
\hline 5. & 18 Jan 2020 & Kucing Milo & Persian \\
\hline \multicolumn{5}{|c|}{ scabiei) } & & \\
\end{tabular}

Berdasarkan data yang diperoleh pada tabel 1 umur kucing yang terkena skabies di Klinik Intimedipet rata-rata berumur kurang dari satu tahun, kemungkinan tertular dari induk yang sudah terinfeksi scabies sebelumnya. Sedangkan dari jenisnya $80 \%$ menyerang anak2 kucing Persian yang berbulu panjang

\subsection{Pemeriksaan Fisik}

Pemeriksaan fisik bertujuan untuk membantu penegakan diagnosa terhadap pasien. Diagnosa skabies pada kucing dapat dilakukan dengan cara inspeksi gejala klinis yang muncul seperti warna rambut kusam, rambut rontok, permukaan kulit tidak rata karena terjadi alopecia serta keropeng pada kulit. Pemeriksaan fisik dilakukan dengan memeriksa adanya keropeng dibagian telinga, hidung, ekor, kaki depan serta kaki belakang kucing.

\subsection{Gejala Klinis}

Hewan terlihat tidak tenang karena rasa gatal dengan menggaruk atau bahkan menggosok bagian yang gatal pada benda keras. Ketika kucing menggaruk bagian yang gatal, hal tersebut akan mengembangkan papula merah yang pada akhirnya akan mengeras seperti kulit mati. Adanya lesi dengan tepi yang tidak merata disertai keropeng, kulit bersisik dan diikuti terjadinya jaringan kulit. Seiring dengan berjalannya waktu, kulit yang terjangkit Sarcoptes scabiei akan mengeras dan juga menebal, jika infeksi ini tidak segera diobati pada akhirnya infeksi skabies pada kucing akan menyebar keseluruh tubuh. Nafsu makan hewan pun akan menurun, dan pada akhirnya diikuti penurunan berat badan sehingga kucing tampak lebih kurus. Skabies merupakan salah satu penyakit zoonosis (Lawrence et al, 2004).

Gejala lain yang mungkin terlihat adalah dimana bulunya tidak hanya terlihat botak, namun juga terlihat kusut. Perubahan sikap yang paling menonjol dari kucing adalah penderita akan sering menggaruk tubuhnya karena ketidaknyamanan yang dihasilkan oleh kutu. 


\section{Gambar1. Kucing yang terserang scabies}

\subsection{Terapi dan Pengobatan}

Pada klinik Intimedipet, kucing yang terkena skabies dilakukan penanganan sebagai berikut :

\section{Pembersihan Luka}

Pembersihan

luka

dilakukan dengan menggosok bagian yang terkena skabies hingga keropeng terangkat sampai bersih dengan menggunakan kassa yang telah diberi iodine. Penggunaan iodine berguna sebagai antiseptik, karena pada dasarnya penyembuhan skabies dengan cara digosok atau scrapping, sehingga menyakibatkan luka pada penderitanya. Tungau ini hidup dan tinggal di keropeng tersebut, sehingga keropeng yang ada pada kucing harus dibersihkan seluruhnya agar penyebab utama skabies bisa hilang.

\section{Pemberian Permethrin 5\%}

Kucing yang tertular skabies mudah menularkan ke kulit hewan lainnya, sehingga supaya skabies tidak menyebar harus menggunakan salep khusus skabies yaitu Scabimite yang di dalamnya mengandung permethrin $5 \%$. Pemberian permethrin 5\% dilakukan setelah pembersihan luka dan kulit kucing harus dalam kondisi kering. Penggunaan permethrin 5\% dengan cara mengoleskan pada bagian yang terkena skabies. Sebaiknya mengobati menggunakan sarung tangan (gloves) supaya tidak tertular skabies dari kucing. Pemberian Injeksi Obat Anti-Parasit dan Anti-Histamin

Obat anti-parasit yang digunakan adalah ivomec yang di dalamnya mengandung ivermectin $1 \%$. Obat ini disuntikkan melalui subcutan, dengan dosis $0,05 \mathrm{ml} / \mathrm{kg}$ berat badan.

Obat anti-histamin yang digunakan adalah recodryl yang di dalamnyamengandung

diphenhydramine, obat ini untuk
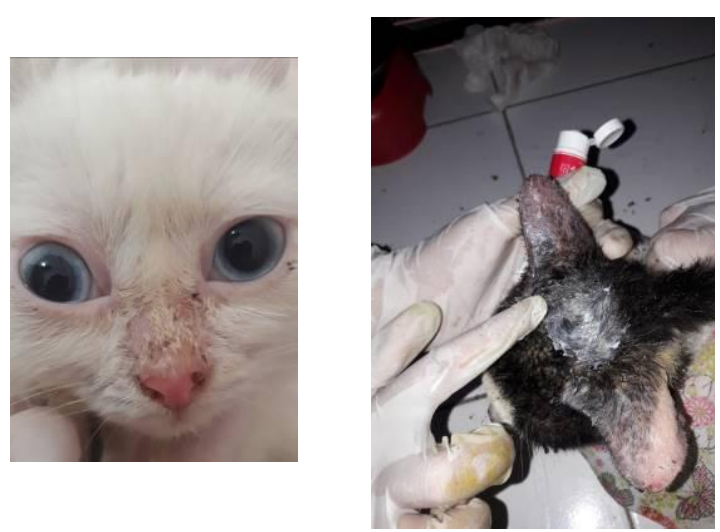

mengatasi rasa gatal yang di derita oleh kucing. Obat ini disuntikkan melalui subcutan, dengan dosis $0,05 \mathrm{ml} / \mathrm{kg}$ berat badan.

Pemberian intermectin
dan recodryl bisa disuntikkan
bersamaan. Kedua obat itu memilki
bahan yang sama yaitu minyak, sehingga
obat bisa dicampurkan bersama. Selain
itu, bisa mengurangi rasa sakit yang
dirasakan oleh kucing jika disuntikkan
bersama.

Agar tidak menulari hewan lain atau manusia di sekitarnya, kucing yang terinfeksi skabies hendaknya dipisahkan selama masa pengobatan. Selain itu kandang, peralatan bermain, peralatan makan, dan alat-alat lainnya hendaknya dibersihkan setiap hari untuk mencegah penularan skabies. Kebersihan pemilik kucing juga harus diperhatikan mengingat penyakit ini bersifat zoonotik (Oakley, 2009).

Lalu lintas perdangan hewan dan produknya ke seluruh wilayah di Indonesia atau internasional membuka pintu penyebaran penyakit menular semakin luas. Penularan skabies yang relatif cepat menjadi tantangan bagi dunia veteriner dan kesehatan manusia. Rendahnya kesadaran serta pengetahuan masyarakat mengenai penyakit skabies, harga obat yang relatif mahal masih perlu mendapat perhatian dari kalangan praktisi kesehatan hewan maupun manusia. Selain itu dibutuhkan juga perhatian dari pemerintah untuk mengendalikan penyakit skabies. 


\section{KESIMPULAN DAN SARAN}

Penyakit skabies merupakan penyakit yang disebabkan oleh tungau Sarcoptes Scabiei, dengan predileksi di permukaan kulit. Penyakit skabies merupakan penyakit zoonosis, sehingga apabila hewan peliharaan yang terserang penyakit skabies sebaiknya segera dilakukan pengobatan secara intensif. Pengobatan yang dilakukan dengan tidak tuntas dapat menyebabkan infeksi sekunder pada luka yaitu infeksi jamur dan bakteri yang menyebabkan bau busuk. Penanganan skabies di Indonesia sudah dapat dilakukan di klinik dokter hewan terdekat. Kesadaran pemilik hewan kesayangan, khususnya anjing dan kucing harus ditingkatkan dengan selalu menjaga kebersihan kandang, peralatan makan, serta peralatan bermain.

\section{DAFTAR PUSTAKA}

Alexander, J .O . 1984 . Scabies : Arthropods and Human Skin. New York: Springer - Verlag . pp . $227-292$.

Arlian LG, Morgan MS. 2017. A review of Sarcoptes scabiei: past, present, and future. Parasit Vectors. 10(1): 297-319.

Arlian, LG. 1989. Biology, Host Relation, and Epidemiology of Sarcoptes Scabiei. Annual Review of Entomologi. 34:139161.

Budiantono. 2004. Kerugian Ekonomi Akibat Skabies dan Kesulitan dalam Pemberantasannya. Bali:Jurnal Penelitian BBVet Denpasar . 1

Buffet, N. and N. Dupin. 2003. Current treatments for scabies. Fundam. Clin. Pharmacol. 17(2): 217-225.

Centers for Disease Control and Prevention (CDC). 2010. Parasite-Scabies. Retrieved May
4, 2014, from Centers for Disease Control and Prevention: http://www.cdc.gov/parasites/sca bies/biology.html. Diakses pada tanggal 5 Mei 2014. Pukul: 20.00 .

Flynn, R.J. 2002. Parasites Of Laboratory Animal. The Lowa State University Press. Ames. Lowa.

Hengge UR, Currie BJ, Jager G, Lupi O, Schwartz RA.2006. Scabies: a ubiquitous neglected skin disease. Lancet Infect Dis. 6(12):769-779

Huang HP, Liang SL, Yang HL, and Chen KY. 1998. Sarcoptes scabiei Infestation in a Cat. http: // www. Innovet.com /journalis /felprac/ abstr98/ 260202.htm [11 November 2011].

Kelly WR. 1984. Veterinary Clinical Diagnostics Third Edition. London : Baillire Tindall.

Lawrence, G., J . Leafasia, J . Sheridan, S . Hills, J . Wate, C. Wate, J . Montgomery, N . Pandeya And D. Purdie . 2004 . Control Of Scabies, skin sores and haematuria in children in the Solomon Islands : Another role for ivermectin. Bull. WHO. 83(1) : 34-42.

Levine, N.D. 1990. Text Book of Veterinary Parasitology. Bursess Publishing Company. New York. pp. 325328 .

McCarthy, JS, Kemp, D, dan Currie, BJ. 2004. Scabies : more than just an irritation. Postgraduate Medical Journal. 80:382-387.

Nahm J \& Corwin RM. 1997. Arthropoda. http: // www.missouri.edu.html /vmicroc / arthropod/ arachnids / scabies.htm $\quad[19$ November 2011].

Oakley, A. 2009. Scabies.Diagnosis and Management. Best Practice Journal. (19):12-16. 
Setiawan Prayogi, Betta Kurniawan. 2016. Pengaruh Personal Hygiene Dala Pencegahan Penyakit Skabies. Vol. 5. No. 5.

Sischo, W.M., Ihrke, P.J., Franti, C.E., 1989. Regional distribution of 10 common skin diseases in dogs. J. Am. Vet. Med. Assoc. 195, 752756.

Soeharsono. 2007. Penyakit Zoonotik Pada Anjing Dan Kucing. Kanisius : Yogyakarta.

Sungkar S. 2004. Parasitologi Kedokteran. Penyakit Yang Disebabkan Artropoda. Balai penerbit FKUI. Jakarta.

Taylor MA, Coop RL, Wall RL. 2007. Veterinary Parasitology. Ed ke-3. Oxford (GB): Blackwell Publishing.

Triplehorn C.A., Johnson N.F. (2005). Borror and delong's introduction to the study of insec. Ed. 7. Thomson Brooks/Cole: Belmon

Urquhart, G.M., J. Armaur, H. Duncan, A.M. Doon and F.W. Jenning. 1989. Veterinary Parasitology. Long Man Scientific and Technical. New York. pp. 184 187.

Urquhart,G.M.,Armour,J.,Duncan,J.L.,D unn,A.M.,Jennings,F.W.,1996.Ve terinaryentomology.In:Urquhart, G.M., Armour, J., Duncan, J.L., Dunn, A.M., Jennings, F.W. (Eds.), Veterinary Parasitology, 2nd Edition. Blackwell Scientific Publications, Oxford, pp. 190201.

Walton, S, Myerscough, M, dan Currie, B. 2000. Studies in vitro on the relative efficacy of current acaricides for Sarcoptes scabiei var. hominis. Trans R Soc Trop Med Hyg. 94 (1):92-96.

Wardhana AH, Manurung J, Iskandar T. 2006. Skabies: tantangan penyakit zoonosis masa kini dan masa datang. Wartazoa. 16(1): 40-52.

\section{APPENDIX}

NB: PANJANG JURNAL 13 - 15 HALAMAN. 